\title{
Future Research Prioritization: Implantable Cardioverter-Defibrillator Therapy in Older Patients
}

\author{
Sana M. Al-Khatib, M.D., M.H.S. ${ }^{1}$, Jennifer M. Gierisch, Ph.D., M.P.H., ${ }^{1,2,3}$, \\ Matthew J. Crowley, M.D. ${ }^{1,2,3}$, Remy R. Coeytaux, M.D., Ph.D. ${ }^{2,4}$, Evan R. Myers, M.D., M.P.H. ${ }^{2,5}$, \\ Amy Kendrick, R.N., M.S.N. ${ }^{2}$, and Gillian D. Sanders, Ph.D. ${ }^{1,2}$ \\ 'Department of Medicine, Duke University School of Medicine, Durham, NC, USA; ${ }^{2}$ Duke Evidence Synthesis Group, Duke Clinical Research \\ Institute, Durham, NC, USA; ${ }^{3}$ Center for Health Services Research in Primary Care, Durham Veterans Affairs Medical Center, Durham, NC, USA; \\ ${ }^{4}$ Department of Community and Family Medicine, Duke University School of Medicine, Durham, NC, USA; ${ }^{5}$ Department of Obstetrics and \\ Gynecology, Duke University School of Medicine, Durham, NC, USA.
}

BACKGROUND: Although the implantable cardioverterdefibrillator (ICD) is highly effective therapy for preventing sudden cardiac death, there is considerable uncertainty about its benefits and harms in older patients, especially in the presence of factors, other than old age, that increase the risk of death.

OBJECTIVE: To develop a prioritized research agenda for the Patient-Centered Outcomes Research Institute as informed by a diverse group of stakeholders on the use and outcomes of the ICD in older patients.

DESIGN:The existing literature was reviewed to identify evidence gaps, which were then refined by engaged stakeholders. Using a forced-ranking prioritization method, the stakeholders ranked evidence gaps by importance. For the highest-ranked evidence gaps, relevant recent studies were identified using PubMed, and relevant ongoing trials were identified using ClinicalTrials.gov.

PARTICIPANTS: Eighteen stakeholders, including clinical experts and researchers in the prevention of sudden cardiac death and ICD therapy, representatives from federal and non-governmental funding agencies, representatives from relevant professional societies, health care decision-makers and policymakers, and representatives from related consumer and patient advocacy groups

KEY RESULTS: The top 12 evidence gaps prioritized by stakeholders were related to the safety and effectiveness of ICDs in older patient subgroups not well represented in clinical trials, predictors of SCD, the impact of the ICD on quality of life, the use of shared decision-making, disparities in ICD use, risk stratification strategies, patient preferences, and distribution of modes of death in older patients.

CONCLUSIONS: In this paper, we identify evidence gaps of high priority for current and future investigations of ICD therapy. Addressing these gaps will likely resolve

Electronic supplementary material The online version of this article (doi:10.1007/s11606-015-3411-6) contains supplementary material, which is available to authorized users.

Received February 20, 2015

Revised April 29, 2015

Accepted May 11, 2015

Published online May 27, 2015 many of the uncertainties surrounding the use and outcomes of the ICD in older patients seen in clinical practice.

KEY WORDS: stakeholder engagement; cardiovascular disease; decision making.

$\mathrm{J}$ Gen Intern Med 30(12):1812-20

DOI: $10.1007 / \mathrm{s} 11606-015-3411-6$

(C) Society of General Internal Medicine 2015

\section{INTRODUCTION}

Sudden cardiac death (SCD) is the most common mode of death in the United States; it claims the lives of approximately 350,000 people each year. ${ }^{1,2}$ The risk of SCD can be significantly reduced with an implantable cardioverter defibrillator (ICD), as evidenced by several randomized clinical trials. ${ }^{3-7}$ Although those trials have informed current practice guidelines on the utilization of primary prevention ICDs, they did not address many areas of immense clinical importance. ${ }^{8}$ One of these areas is the efficacy, effectiveness, and safety of the ICD in older patients ( $\geq 75$ years of age). While clinical trials of primary prevention ICDs did not exclude older patients, the mean or median age of patients who were enrolled was well below 75 years. $^{3-7}$

In a previous study, our group pooled patient-level data from five randomized clinical trials of primary prevention ICDs $(n=3,530) .{ }^{9}$ After adjusting for potential confounders, we found that although primary prevention ICDs conferred survival benefit to older patients, this survival advantage attenuated with advancing age. Moreover, the number of patients older than 75 years in that study was relatively small, and this may have affected the results. ${ }^{9}$ In an analysis of ICD effectiveness in the American Heart Association Get With the Guidelines-Heart Failure registry database, although receipt of ICD therapy was associated with a lower risk of 3-year mortality in patients 65 to 74 years of age, there was only a trend toward improved survival in patients 75 to 84 years of age (adjusted hazard ratio [HR] $0.65,95 \%$ CI $0.47-0.89$ among patients 65 to 74 years; HR 
$0.80,95 \%$ CI $0.62-1.03$ among patients $75-84$ years). ${ }^{10}$ Therefore, data on the role of primary prevention ICDs in patients $\geq 75$ years of age remain inconclusive.

Despite the lack of definitive evidence on the outcomes of primary prevention ICDs in older patients, ICD implantation has become widespread in this population. In the National Cardiovascular Data Registry (NCDR), which captures the majority of primary prevention ICDs implanted in the United States, the mean age of patients receiving an ICD was $67 \pm$ 13 years. ${ }^{11}$ One study of that dataset showed that more than $40 \%$ of new ICDs are implanted in patients over 70 years of age. ${ }^{12}$ This underscores the importance of conducting studies aimed at examining the outcomes of primary prevention ICDs in patients $\geq 70-75$ years of age.

There are reasons that outcomes of primary prevention ICDs in the elderly may differ from those of their younger counterparts. Older patients who are eligible for a primary prevention ICD because of heart failure typically have other comorbidities that increase the likelihood of non-sudden cardiac death, an outcome not affected by the ICD. Additionally, older patients may be frail, and this, along with the coexistence of several comorbidities, may increase the risk of procedural complications and can have a major negative impact on their quality of life, raising concerns about therapies-like the ICD - that prolong life but do not necessarily improve its quality.

Given the clinical importance of SCD, the lack of data regarding the optimal use of ICDs in older patients, the variety of patient-centered outcomes of interest, and areas of uncertainty, we sought to create a prioritized research agenda for the Patient-Centered Outcomes Research Institute (PCORI) that would incorporate different stakeholders' perspectives.

A central goal of PCORI is to engage stakeholders in its work in a meaningful way. Between September 2012 and January 2013, PCORI undertook a broad effort to solicit research topics from patients, caregivers, and researchers, and from results of previous prioritization processes by groups such as the Institute of Medicine, that could be considered for targeted funding. In 2014, PCORI's Assessment of Prevention, Diagnosis, and Treatment Options program, together with the program's external advisory panel, identified the use of ICDs in older patients as an important topic with unmet research needs. PCORI tasked the Duke University Evidence Synthesis Group (ESG) with the responsibility of working with various stakeholders to identify and prioritize future research opportunities on this topic that were most needed by patients and other decision-makers.

\section{METHODS}

\section{Overview of Prioritization Approach}

Our approach to prioritizing future research and developing recommendations for targeted future funding by PCORI included several steps (Fig. 1), which broadly followed those developed as part of the Agency for Healthcare Research and Quality (AHRQ)'s Evidence-based Practice Center (EPC) Program ${ }^{13}$ for identifying and prioritizing future research needs. These steps involved appraisals of recent systematic reviews to preliminarily identify important evidence gaps, transformation of evidence gaps into research questions, engagement of stakeholders to identify additional gaps and prioritize research needs or questions, and scans of recently published and ongoing studies relevant to the stakeholders' list of priorities. Given the needs of PCORI, we did not explore study design considerations during this project.

\section{Identification of Evidence Gaps}

We used an iterative process to identify evidence gaps for ICD use in older patients. First, we identified and appraised recent published systematic reviews, clinical practice guidelines, and future research needs documents in order to develop an initial list of evidence gaps. This list was neither exhaustive nor prioritized. Next, we organized these gaps according to broad themes and transformed them into research questions. These initial evidence gaps were distributed to our stakeholder group, who was tasked with reviewing and suggesting additional questions for prioritization. These suggestions were reviewed by our team, overlapping topics were combined, and we produced a global revised evidence gap list which represented unique gaps in evidence across the broad themes. This final list was circulated to the stakeholder team for review to ensure that our edits reflected their proposed additions.

\section{Selection and Engagement of Stakeholders}

We solicited participation from a group of 40 stakeholders, including clinical experts and researchers in the prevention of sudden cardiac death and ICD therapy, representatives from federal and non-governmental funding agencies, representatives from relevant professional societies, health care decision-makers and policymakers, and representatives from related consumer and patient advocacy groups (Table 1). Within each of these categories, we sought to identify a person who was either familiar with the clinical area and its current uncertainties or who brought a specific methodological expertise to the stakeholder panel. We solicited and received stakeholder input at various points in the process through email detailing the process and outlining existing evidence gaps, and a Web-based survey to obtain priority ranking of topics.

\section{Prioritization of Future Research}

After the identified research priorities had been expanded, stakeholders were invited to rank the revised future research 


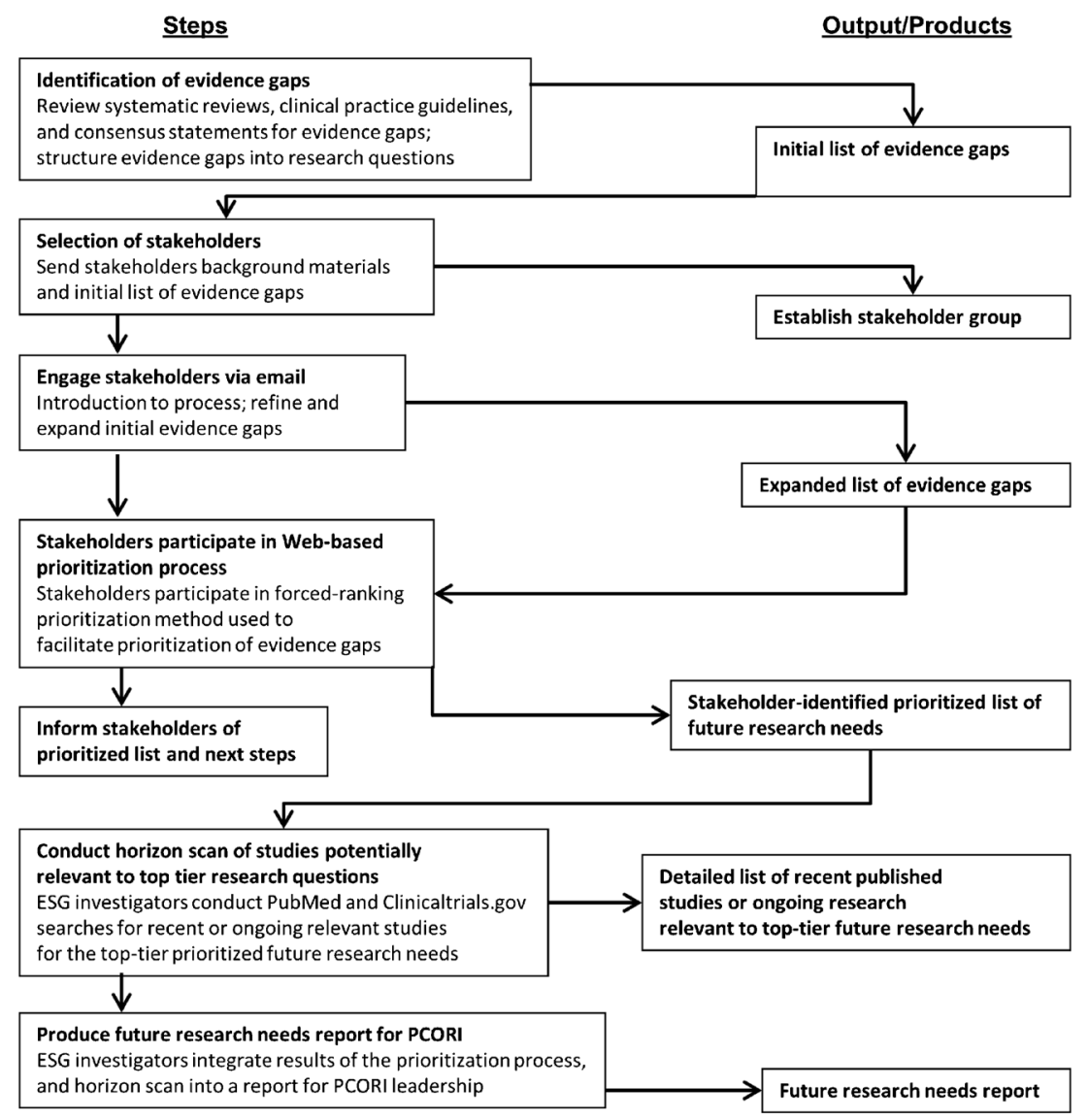

Figure 1 Overview of prioritization process. Adapted from Ip S, Raman G, Concannon T, et al. Intravascular Diagnostic Procedures and Imaging Techniques Versus Angiography Alone in Coronary Artery Stenting: Future Research Needs. Future Research Needs Paper No. 25. (Prepared by Tufts Evidence-based Practice Center under Contract No. 290-2007-10055-I.) AHRQ Publication No. 13-EHC016-EF. Rockville, MD: Agency for Healthcare Research and Quality. February 2013. Available at: www.effectivehealthcare.ahrq.gov/reports/final.cfm. Accessed March 3, 2015. Abbreviations: ESGEvidence Synthesis Group, PCORIPatient-Centered Outcomes Research Institute

needs online. The survey used a forced-ranking prioritization method described by the AHRQ EPC's Future Research Needs projects, ${ }^{13}$ whereby participants were given 17 votes that could be allocated to any identified research priorities, with a maximum of three votes per item. The stakeholders were not given specific prioritization criteria to use, but rather were told to determine, on the basis of their perspectives, the most important unanswered research questions on the use of ICD therapy in older patients. We also asked stakeholders to self-report their perspective, understanding that an individual stakeholder could represent more than one perspective. Possible perspectives included patients and the public, providers, purchasers, payers, policymakers, product makers, and principal investigators. Only priorities in the top tier that were ranked as top priority by at least one-third of stakeholders (i.e., by at least six stakeholders) moved on to the final stage of horizon scan $(n=12)$. We performed only one ranking of the topics. Stakeholders were informed of the final ranking of future research priorities. All topics and their rankings were presented to PCORI for consideration, with top-tier topics including horizon scan evidence.

\section{Horizon Scan of Studies Potentially Relevant to Top-Tier Research Questions}

We performed two database searches to identify recently published and ongoing studies relevant to the top-tier future research questions as indicated by stakeholder prioritization. We searched PubMed to identify relevant literature published during the past 5 years and ClinicalTrials.gov for ongoing and recently completed studies. For the ClinicalTrials.gov search, we used the keywords "ICD" OR ("defibrillator" AND "implantable") and focused on senior populations and Phase 3 or 4 studies. Appendix A (available online) provides the exact search strategy used for PubMed.

Members of the ESG team reviewed the titles and abstracts identified by searching PubMed for applicability. Articles were included if they met all of the following criteria: presented original data or secondary analysis of data from an RCT, prospective or retrospective observational study, or relevant modeling study; included data related to ICD use and the prevention of sudden cardiac death; potentially included data on patients aged 65 and older; and had a stated objective that could be categorized according to our identified list of research priorities. 
For the ClinicalTrials.gov search, a member of the ESG team reviewed all study abstracts identified by the search and coded them as potentially relevant to one or more of the identified research priorities. We then abstracted study type (such as observational or RCT), recruitment status, and sample size.

\section{Role of the Funding Source}

This work was funded by PCORI, who stipulated the topic for prioritization but did not participate in the literature search, determination of study eligibility criteria, data analysis or interpretation, or preparation or approval of the manuscript for publication. PCORI reviewed a draft version of the manuscript.

\section{RESULTS}

\section{Expansion of Evidence Gaps Through Stakeholder Engagement}

Of the 40 solicited stakeholders, 22 (55\%) provided input and helped expand the initial list of 22 evidence gaps to 48 . These stakeholders represented the diverse perspectives targeted in Table 1. The gaps were consolidated to eliminate overlapping topics and were organized in to three broad themes:

1. Evidence gaps in ICD effectiveness in subgroups of older individuals specified by factors other than old age that predispose to increased mortality

2. Evidence gaps in safe deployments of ICDs in older individuals, with and without comorbidities

3. Evidence gaps in adoption of ICDs in older individuals

\section{Stakeholder Ranking of Future Research Needs}

Table 2 (e-only) shows the 48 final potential research topics and stakeholder rankings. Eighteen stakeholders completed the prioritization exercise. We also indicate in Table 2 the number of stakeholders who voted for each specific research topic and the diverse perspectives represented by these votes. Across the 18 stakeholders, five self-identified as patients, 13 as providers, four as policymakers, two as product makers, and eight as principal investigators. No stakeholders self-identified as purchasers or payers.

The top 12 future research needs prioritized by stakeholders were related to the safety and effectiveness of ICDs in older patient subgroups not well represented in clinical trials, predictors of SCD, the impact of ICD use on quality of life, the use of shared decision-making, disparities in ICD referrals, risk stratification strategies, patient preferences, effect of ICD use on geriatric outcomes, and distribution of modes of death in older patients.

Of note, 5 of the top 12 evidence gaps were topics suggested by the stakeholder group, only two topics (both suggested by stakeholders) received no votes. and of the 15 lowest-tier topics, 11 were suggested by stakeholders, perhaps indicating that these topics were of interest to an individual stakeholder but not the broader group. The top-tier topics in general had support from all included perspectives.

\section{Horizon Scan of Studies Potentially Relevant to Top-Tier Research Questions}

The horizon scan demonstrated a high-level match between overall stakeholder priorities and recent or ongoing research. Seven of the prioritized research needs had more than a dozen recent or ongoing studies. The prioritized areas with the greatest number identified potential studies of interest included the prediction of SCD $(n=47)$, potential risk stratification strategies $(n=31)$, impact of ICD use on survival and quality of life $(n=29)$, and the safety and effectiveness of ICDs in subgroups not well represented in clinical trials $(\mathrm{n}=27)$.

Our PubMed search identified 1020 articles. Of these, 121 met our inclusion criteria, and included seven systematic reviews, 2 RCTs, 109 cohort studies, one case-control study, and two other studies. Sample size ranged from 12 to over 250,000 . Only nine studies were active comparator studies; 17 studies either were placebo-controlled or used standard of care as the comparison, and 95 studies had no comparator. Only three studies were potentially applicable to the shared decision-making topic, and only two studies focused on efforts to reduce disparities in ICD referrals. Of note, our horizon scanning did not allow us to determine whether the study specifically included data on older patients although studies where the mean age of the included cohort was $\leq 60$ years of age were excluded. Of the 121 included studies, only 23 explicitly focused on older patients or on age as a predictor (shaded grey in Table 2).

Our search of ClinicalTrials.gov yielded 232 studies. Of these, 105 did not appear to meet eligibility based on the ICD use in elderly question (looking at intervention and population fields), and another 40 had been terminated or had withdrawn prior to study completion. Of the remaining 87 studies, 16 were open and enrolling, and 71 had been completed. We identified ten protocols as potentially relevant to the top-tier research questions. These protocols were a mix of study designs: eight RCTs and two non-randomized interventional trials. Sample size ranged from 85 to 1400 patients.

Two of the prioritized research questions had no identified ongoing studies. These included determining predictors of SCD vs. non-SCD in older patients and the topic focusing on exploring modes of death in older patients at risk for SCD. The Tables in Appendix B (available online) detail key characteristics of the included PubMed and ClinicalTrials.gov articles separately for each of the top-tier future research needs.

\section{DISCUSSION}

This article outlines our process for developing a prioritized research agenda for PCORI as informed by a diverse group of 
Table 1 Stakeholder organizations and perspectives

\begin{tabular}{ll}
\hline \hline Organization & $\begin{array}{l}\text { Stakeholder } \\
\text { perspective }\end{array}$ \\
\hline $\begin{array}{l}\text { American College of } \\
\text { Cardiology }\end{array}$ & $\begin{array}{l}\text { Professional societies/ } \\
\text { researchers }\end{array}$ \\
American Heart Association & $\begin{array}{l}\text { Professional societies/ } \\
\text { researchers }\end{array}$ \\
\hline
\end{tabular}
researchers

\section{American Geriatrics Society}

Professional societies/ researchers

\section{Agency for Healthcare \\ Research and Quality}

Boston Scientific

Heart Rhythm Society

Medtronic

National Cardiovascular Data Registry (NCDR)-ICD Registry

National Heart, Lung, and Blood Institute

Patient Advocate

St. Jude Medical

Sudden Cardiac Arrest Association

Consumer and patient advocacy

Health care decisionand policymakers

Patient advocacy

Product makers

Product makers

Professional societies/ researchers

Product makers

Professional societies/ researchers Professional societies/
researchers

Thought Alliance

WomenHeart

\section{Purpose}

The ACC strives to achieve its enduring purpose: to improve cardiovascular health through education, research, quality care and health policy. The members of the College will dramatically reduce the incidence, severity and complications of cardiovascular disease as we promote prevention, reduce disparities in health care, and improve personal and population-based cardiovascular health.

The American Heart Association is the nation's oldest, largest voluntary organization devoted to fighting cardiovascular diseases and stroke. Founded by six cardiologists in 1924, the AHA now includes more than 22.5 million volunteers and supporters, and funds innovative research, fights for stronger public health policies and provides lifesaving tools and information to save and improve lives.

The American Geriatrics Society (AGS) is a not-for-profit organization of over 6,000 health professionals devoted to improving the health, independence and quality of life of all older people. The Society provides leadership to health care professionals, policymakers and the public by implementing and advocating for programs in patient care, research, professional and public education, and public policy. The Agency for Healthcare Research and Quality's (AHRQ) mission is to produce evidence to make health care safer, higher quality, more accessible, equitable, and affordable, and to work within the U.S. Department of Health and Human Services and with other partners to make sure that the evidence is understood and used. Company that is a leading innovator of medical solutions that improve the health of patients around the world. Products and technologies are used to diagnose or treat a wide range of medical conditions, including heart, digestive, pulmonary, vascular, urological, women's health, and chronic pain conditions.

The Heart Rhythm Society (HRS) is a leading resource on cardiac pacing and electrophysiology. This specialty organization represents medical, allied health, and science professionals from more than 70 countries who specialize in cardiac rhythm disorders.

Medtronic is the world's largest medical technology company, offering innovative therapies to fulfill their mission of alleviating pain, restoring health, and extending life. Their medical therapies treat cardiac and vascular diseases, diabetes, and neurological and musculoskeletal conditions.

The ICD Registry ${ }^{\mathrm{TM}}$ establishes a national standard for understanding treatment patterns, clinical outcomes, device safety, and the overall quality of care provided to implantable cardioverter defibrillator (ICD) patients. As the CMS-mandated registry for hospitals that perform ICD implantation procedures, the ICD Registry plays an important role in determining the association between evidence-based treatment strategies and clinical outcomes. Eighty percent of participating hospitals value the registry beyond the CMS mandate - capturing all ICD implantations regardless of payer or indication.

The National Heart, Lung, and Blood Institute (NHLBI) provides global leadership for a research, training, and education program to promote the prevention and treatment of heart, lung, and blood diseases and enhance the health of all individuals so that they can live longer and more fulfilling lives.

To represent research priorities and issues from the patient's perspective.

Company with mission to transform the treatment of expensive epidemic diseases, including atrial fibrillation, heart failure, stroke, coronary artery disease, congenital heart defects, Parkinson's disease and chronic pain. St. Jude Medical provides innovative solutions that reduce the economic burden of costly diseases on health care systems worldwide and provide improved outcomes for patients.

The Sudden Cardiac Arrest Association (SCAA) is an organization singularly focused on sudden cardiac arrest. SCAA identifies and unites survivors and those at risk of sudden cardiac arrest, as well as others who are interested in being advocates on SCAA issues in their communities and beyond. Their membership is dedicated to promoting solutions to prevent sudden cardiac death, including increased awareness, immediate bystander action, public access to defibrillation (PAD), cardiovascular disease prevention, and access to preventative therapies.

The Sudden Cardiac Arrest Thought Leadership Alliance (SCATLA) was formed to improve the quality of care around sudden cardiac arrest (SCA) and to share and develop educational tools for patients and health care providers.

WomenHeart's mission is to improve the health and quality of life of women living with or at risk of heart disease, and to advocate for their benefit.

Abbreviations not defined above: ACCAmerican College of Cardiology, AHAAmerican Heart Association, CMSCenters for Medicare \& Medicaid Services, PAD public access defibrillation

stakeholders. Based on a review of the existing literature and with input from various stakeholders, we developed a list of 48 potential future research topics in ICD use in older patients. The stakeholders prioritized these topics through a forcedranking process. We then examined recently published and ongoing studies to identify research relevant to the top 12 future research priorities in order to assist PCORI in developing future targeted funding opportunities.

Of the top 12 future research priorities, three topics (\#2, 6 and 12 from Table 2) were directly related to risk stratification. This is not surprising, as the decision to recommend a primary prevention ICD to a given patient is currently largely based on 
Table 2 (e-only) Final ranking of future research needs for ICD in older patients*

\begin{tabular}{lll}
\hline \hline Question & Score & $\begin{array}{l}\text { Stakeholders, } \\
n\end{array}$ \\
Perspectives $^{\dagger}$
\end{tabular}

Top tier

1. What is the safety and effectiveness of primary prevention ICDs in older patient subgroups not included or not well represented in clinical trials (e.g., patients with multiple comorbidities, patients with advanced kidney disease, age $>80$, etc.)?

2. What are the predictors of SCD vs. those of non-SCD in older primary prevention ICD patients, i.e., at what level of competing (non-SCD) mortality risk are ICDs no longer effective in reducing all-cause mortality?

3. How do ICD shocks, ICD use and follow-up, and complications of ICD use affect survival and quality of life in older patients? Does the impact vary by age, gender, or comorbidity status?

4. Does facilitated shared decision-making with older patients, their families or caregivers, and their providers affect ICD treatment choices and prevention of sudden cardiac death outcomes?

5. Are there disparities in ICD referrals in older patients by sex, race, or ethnicity?

6. What is the comparative safety and effectiveness of risk stratification strategies in older patients for SCD beyond using LVEF?*

7. What are effective methods to reduce health care disparities in the use of primary (or secondary) prevention ICDs in older patients?

8. What are patient preferences regarding improved survival from ICDs at the possible cost of comorbidities/complications/suffering vs. shorter survival but with quick and "painless" death?"

9. What is the comparative safety and effectiveness of available devices (transvenous single-chamber ICD, transvenous dual-chamber ICD, subcutaneous ICD) for an individual older patient based on his/her age, underlying heart disease and the presence of other diseases?

10. What is the effect of ICD intervention on universal geriatric outcomes such as quality of life, physical activity, independence, fatigue and frailty?

11. Is there an upper age limit beyond which it becomes futile to expect a benefit from an ICD, i.e., where the increase in survival is minimal compared to patients without an ICD, and there is no or minimal increase in quality-adjusted life years?

12. What is the distribution of modes of death in older patients who are eligible for a primary (or secondary) prevention ICD?

Middle tier

13. What patient-reported outcome metrics for quality of life and device adjustment are most informative in ICD research trials of older patients?

14. What is the comparative safety and effectiveness of remote monitoring of ICD devices versus standard clinic visits for older patients seen in clinical practice?

15. What is the comparative effectiveness of available methods to enhance communication about ICD deactivation as an ongoing process that starts prior to implant and continues over time as patients' health status and goals of care change?

16. Is there a role for subcutaneous ICDs in older patients with a primary or secondary prevention indication for the device?

17. What is the comparative effectiveness of various decision support tools to assist patients, caregivers, and providers in determining the appropriate timing for ICD deactivation?

18. How do we optimize the safety of ICDs and leads in older patients?

19. What factors influence ICD remote monitoring adoption and utilization in older patients?

20. What patient-centered or comorbidity-specific outcomes influence the overall effectiveness of ICDs in older adults? $?^{* \star}$

21. What is the clinical effectiveness and safety of ICD replacements in older patients who have not had an appropriate shock?

22. What is the additional value of novel markers (like genetic markers, MRI findings, and biomarkers) to predictive models that utilize clinical and mostly conventional risk factors for the prediction of SCD in older patients?

23. What is the current utilization of ICDs in eligible patients $>65$ ? What are the barriers to utilization? ${ }^{* \dagger}$

24. What are patient preferences regarding communications from their health care providers about the benefits and burdens of device therapy and how they might align with their desired outcomes for their health care?
3 patients, 7 providers, 2 policymakers, 2 PIs 5 PIs PIs 4 PIs

1 patient, 5 providers, 2 2 PIs 1 product maker, 1 PI PIs 1 product maker, 4 PIs 5 PIs 4 PIs makers, 2 PIs 1 PI 3 PIs 1 PI 3 PIs 3 PIs maker, 2 PIs
1 patient, 7 providers, 2 policymakers,

4 patients, 4 providers, 4 policymakers, 3

4 patients, 4 providers, 2 policymakers,

policymakers, 1 product maker,

1 patient, 6 providers, 2 PIs

1 patient, 5 providers, 3 policymakers,

2 patients, 4 providers, 1 policymaker, 3

3 patients, 5 providers, 1 policymaker,

2 patients, 6 providers, 1 policymaker,

5 providers, 1 policymaker, 2 PIs

1 patient, 5 providers, 1 policymaker,

1 patient, 3 providers, 3 PIs

2 patients, 3 providers, 2 product

1 patient, 3 providers, 1 policymaker,

1 patient, 4 providers, 1 product maker,

2 patients, 3 providers, 1 policymaker,

1 patient, 2 providers, 2 PIs

1 patient, 3 providers, 2 product makers,

4 providers, 1 policymaker, 3 PIs

1 patient, 4 providers, 1 policymaker,

4 providers, 2 policymakers, 1 PI

4 providers, 1 policymaker, 1 product

2 patients, 2 providers, 1 policymaker, 1 PI 
Table 2. (continued)

\begin{tabular}{|c|c|c|c|}
\hline Question & Score & $\begin{array}{l}\text { Stakeholders, } \\
n\end{array}$ & Perspectives $^{\dagger}$ \\
\hline $\begin{array}{l}\text { 25. What evidence is needed to better enable a patient-centric approach to } \\
\text { end-of-life decision-making for ICD recipients? }\end{array}$ & 7 & 3 & $\begin{array}{l}2 \text { patients, } 2 \text { providers, } 1 \text { product maker, } \\
1 \text { PI }\end{array}$ \\
\hline $\begin{array}{l}\text { 26. Are there sex differences in any of the above safety and effectiveness } \\
\text { questions regarding ICD therapy in older patients? }\end{array}$ & 5 & 3 & $\begin{array}{l}2 \text { patients, } 2 \text { providers, } 1 \text { policymaker, } \\
1 \text { PI }\end{array}$ \\
\hline $\begin{array}{l}\text { 27. What is the effect of ICD intervention on cognitive trajectory in } \\
\text { persons with mild cognitive impairment/early dementia? }\end{array}$ & 4 & 4 & 1 patient, 2 providers, 1 policymaker, $1 \mathrm{PI}$ \\
\hline $\begin{array}{l}\text { 28. What is the comparative safety and effectiveness of strategies to } \\
\text { minimize short- and long-term complications of ICDs in older } \\
\text { patients receiving these devices? }\end{array}$ & 4 & 3 & 1 patient, 2 providers, 2 PIs \\
\hline $\begin{array}{l}\text { 29. How does remote monitoring of ICDs in older patients impact patient } \\
\text { outcomes including quality of life and activity? }\end{array}$ & 4 & 2 & $\begin{array}{l}1 \text { patient, } 1 \text { providers, } 1 \text { policymaker, } \\
1 \text { product maker, } 1 \text { PI }\end{array}$ \\
\hline $\begin{array}{l}\text { 30. Do specific types of patient comorbidities affect older patients' } \\
\text { acceptance of ICD therapy and/or provider willingness to } \\
\text { recommend? }\end{array}$ & 4 & 2 & $\begin{array}{l}1 \text { patient, } 2 \text { providers, } 1 \text { product maker, } \\
2 \text { PIs }\end{array}$ \\
\hline $\begin{array}{l}\text { 31. Is the beneficial effect of the ICD in older patients durable beyond the } \\
\text { limited follow-up period of existing clinical trials? }\end{array}$ & 3 & 3 & 3 providers, 1 policymaker \\
\hline $\begin{array}{l}\text { 32. What is the clinical effectiveness and safety of ICD replacements in } \\
\text { older patients who have improved ejection fraction? }\end{array}$ & 3 & 2 & 2 providers, $1 \mathrm{PI}$ \\
\hline $\begin{array}{l}\text { 33. What are the most effective, patient-centered strategies to reduce } \\
\text { anxiety associated with ICD shocks/fear of shocks? }\end{array}$ & 3 & 1 & 1 provider, $1 \mathrm{PI}$ \\
\hline Lower tier & & & \\
\hline $\begin{array}{l}\text { 34. Does higher frequency of prior heart failure hospitalizations identify a } \\
\text { cohort of older patients who will derive less benefit from ICD } \\
\text { therapies? }\end{array}$ & 2 & 2 & 1 provider, 1 policymaker, $1 \mathrm{PI}$ \\
\hline $\begin{array}{l}\text { 35. What are the predictors of appropriate ICD shocks in older patients } \\
\text { with a secondary prevention ICD? }\end{array}$ & 2 & 2 & 1 patient, 2 providers, 2 PIs \\
\hline $\begin{array}{l}\text { 36. How do the outcomes of "optimal programming of ICDs" as } \\
\text { demonstrated by recent randomized clinical trials in older patients } \\
\text { seen in clinical practice compare to those observed in those clinical } \\
\text { trials? }\end{array}$ & 2 & 2 & 1 patient, 1 policymaker, 1 PI \\
\hline $\begin{array}{l}\text { 37. What is the comparative safety and effectiveness of optimally } \\
\text { programmed single-chamber ICDs as compared to optimally } \\
\text { programmed dual-chamber ICDs in older patients? }\end{array}$ & 2 & 2 & 1 patient, 2 providers, 2 PIs \\
\hline $\begin{array}{l}\text { 38. What is the most effective, patient-centered management strategy in } \\
\text { older ICD patients when devices or leads are recalled? }\end{array}$ & 2 & 2 & 2 patients, 1 policymaker \\
\hline $\begin{array}{c}\text { 39. What is the most effective, patient-centered management strategy for } \\
\text { older ICD patients with bloodstream or other serious infections? }\end{array}$ & 2 & 2 & 2 providers, $1 \mathrm{PI}$ \\
\hline $\begin{array}{l}\text { 40. How can the appropriate utilization of primary prevention ICDs in } \\
\text { older patients seen in clinical practice be enhanced? }\end{array}$ & 2 & 2 & 2 providers, 1 PI \\
\hline $\begin{array}{l}\text { 41. What data from device interrogations are older patients most } \\
\text { interested in possessing and why? }{ }^{*}\end{array}$ & 2 & 1 & 1 provider, 1 product maker, 1 PI \\
\hline $\begin{array}{l}\text { 42. What are the predictors of appropriate ICD shocks in older patients } \\
\text { with non-ischemic cardiomyopathy with a primary prevention } \\
\text { ICD? }\end{array}$ & 1 & 1 & 1 patient, 1 provider, 1 PI \\
\hline $\begin{array}{l}\text { 43. What are the predictors of appropriate ICD shocks in older patients } \\
\text { with ischemic heart disease with a primary prevention ICD? }\end{array}$ & 1 & 1 & 1 patient, 1 provider, 1 PI \\
\hline $\begin{array}{l}\text { 44. What is the influence of the caretaker on an older patient's health } \\
\text { management and outcomes related to the prevention of sudden } \\
\text { cardiac } \\
\text { death and ICD therapy? }\end{array}$ & 1 & 1 & 1 patient \\
\hline $\begin{array}{l}\text { 45. Are there socioeconomic factors that differentiate effectiveness of ICD } \\
\text { therapy recommendation or patient acceptance in older patients, e.g., } \\
\text { primary caregiver status, living situation (alone or group setting), } \\
\text { family circumstances, etc.? }\end{array}$ & 1 & 1 & 1 provider, $1 \mathrm{PI}$ \\
\hline $\begin{array}{l}\text { 46. What changes in patient circumstances would alter older patients' } \\
\text { acceptance of ICD therapy? }\end{array}$ & 1 & 1 & 1 provider, $1 \mathrm{PI}$ \\
\hline 47. Does obesity in older patients influence ICD effectiveness or safety? & 0 & 0 & - \\
\hline $\begin{array}{l}\text { 48. In older patients with ICDs, what are the clinical benefits and risks of } \\
\text { the currently used longer-lasting devices? }\end{array}$ & 0 & 0 & - \\
\hline
\end{tabular}

* "Older patients" are defined as patients 75 years of age and older, except in questions flagged with an asterisk $(*)$, which apply to patients 65 years of age and older

† "Perspectives" indicates the self-reported perspectives represented by the stakeholders who voted for the individual evidence gaps. Note that an individual stakeholder could self-identify as representing more than one perspective (i.e., could self-identify as both a patient and a provider); for this reason, the number of perspectives does not necessarily equal the number of stakeholders

Indicates evidence gaps that were added or substantially revised by stakeholders

Abbreviations: ICD(s) implantable cardioverter defibrillator(s), LVEF left ventricular ejection fraction, MRI magnetic resonance imaging, $n$ number (of stakeholders), PI(s) principal investigator(s), SCD sudden cardiac death

a left ventricular ejection fraction of $\leq 35 \%$, the main inclusion criterion in the pivotal randomized clinical trials of primary prevention ICDs. ${ }^{3-8}$ However, an appreciable number of patients with an ICD never receive a therapeutic benefit from it. As such, there is a need for better risk stratification tests in all patients with systolic heart failure, and especially the 
elderly. Because of the presence of several comorbidities in older patients, there are competing modes of death that may reduce the potential benefit from an ICD. Of note, nine previously published studies targeted topic \#2 (SCD vs. non-SCD) and focused explicitly on older populations; two such studies targeted risk stratification strategies (topic \#6), and nine studies in older patients explored modes of death (Appendix B, available online). None of these studies were RCTs, and instead were cohort studies, normally with no comparator.

Two topics (\#5 and 7 from Table 2) of the top 12 future research priorities relate to disparities. This is important, as previous papers have shown significant gender and race disparities in the Medicare patient population. ${ }^{14,15}$ In a survey of practicing cardiologists in the U.S., health care providers were not less likely to recommend an ICD to women and racial minorities, but they were less likely to recommend it to older patients. ${ }^{16}$ Although this may reflect hesitation regarding offering an ICD to patients who are frail and have several comorbidities, this has not been confirmed by that or other studies. Therefore, disparities in ICD use in older patients should be examined. Only three published studies targeting older patients focused on exploring disparities; none of the included studies targeted strategies for reducing these disparities.

Additional efforts are needed to enhance the knowledge of ICD outcomes and factors that could affect outcomes in older patients seen in clinical practice, and to improve the process of decision-making. The latter is particularly important, as determinants of effective and shared decision-making in relation to ICDs have yet to be identified. Our search of the literature shows a dearth of studies (only three) currently examining this issue. These issues are covered by future research priorities 1 , 3, 4, 8, 10 and 11 (Table 2).

Future research priority \#10 covers an important topic, because although single- (involving the insertion of a right ventricular lead only) and dual-chamber ICDs (involving the insertion of a right atrial and a right ventricular lead) have long been on the market, there is still uncertainty as to whether a dual-chamber ICD is superior to a single-chamber device. This is an important question, as the type of device could affect important patient outcomes. While several studies have compared outcomes between single-chamber and dual-chamber ICDs, these investigations had major limitations, yielded conflicting results, and predated the evidence on optimal programming of ICDs. ${ }^{17-32}$ Today's health care providers and patients, therefore, often struggle in making the critical decision of what device type to choose, and professional societies and policymakers are incapable of developing evidence-based recommendations and coverage decisions. ${ }^{8,33}$ These issues are further compounded by the advent of subcutaneous ICDs, whose outcomes, especially in the elderly, are uncertain. Indeed, the mean age of patients enrolled in studies of subcutaneous ICDs was only 54 years. ${ }^{34,35}$ Because older patients are more likely to require pacing that cannot be provided by subcutaneous ICDs, these devices may not be appropriate for older patients. None of the published studies focusing on different device types have explicitly targeted elderly patients.

Our prioritization process was not without limitations. Although we took efforts to be comprehensive, it is possible that the list of future research needs we generated and expanded with stakeholder feedback does not reflect the full range of future research possibilities. In addition, we engaged a relatively small number of stakeholders, and it is possible that another group of stakeholders might rank the identified future research needs differently. Still, we included a diverse stakeholder panel with a range of expertise in determining these priorities, with a particular focus on patient-centered research. Also, because a comprehensive systematic review has not been conducted for many of the identified evidence gaps, we cannot determine with certainty the degree to which prioritized future research needs have already been addressed. Finally, within the scope of this project, and given PCORI's needs, we did not explore the potential study design considerations for the prioritized topics. Such exploration is important in order to consider the feasibility and validity of available study designs and to highlight the design with the least risk of bias but with the greatest likelihood of completion.

ICDs are currently the most effective treatment for patients at risk for SCD. The optimal and most effective use of these life-saving devices in the older population, however, is uncertain. A workgroup of 27 stakeholders representing a host of diverse perspectives identified 12 research areas with the highest priority for future research for patient-centered use of ICDs in older populations, which, if studied, have the potential to resolve some of the uncertainty surrounding the prevention of SCD.

ACKNOWLEDGMENTS: Contributors: The authors thank Megan M. Chobot, M.S.L.S., for project coordination and help with the literature search and retrieval; and Rebecca Gray, D.Phil., for editorial assistance. They also gratefully acknowledge the contributions of members of the stakeholder panel (Anne Curtis, M.D.; Gregg Fonarow, M.D.; Adrian Hernandez, M.D., M.H.S.; Susan Campbell, M.P.H.; Mark Carlson, M.D., M.A.; Laura Blum; Kenneth Stein, M.D.; Andra Thomas; Sam Sears, Ph.D.; Michael Mirro, M.D.; Dan Schaber, Pharm.D.; David Hayes, M.D.; Paul Dorian, M.D.; Riccardo Cappato, M.D.; Alan Kadish, M.D.; Peter Kudenchuk, M.D.; Jodie Hurwitz, M.D.; Dan Matlock, M.D., M.P.H.; Mary Tappe; Cathleen Colon-Emeric, M.D. M.H.S.; Heather Whitson, M.D., M.H.S.; Elise Berliner, Ph.D.; Frederick Masoudi, M.D., M.S.P.H.; Clyde Yancy, M.D., M.Sc.; Fred Kusumoto, M.D.).

Funders: This work was funded by PCORI, who stipulated the topic for prioritization but did not participate in the literature search, determination of study eligibility criteria, data analysis or interpretation, or preparation or approval of the manuscript for publication. PCORI reviewed a draft version of the manuscript and provided suggestions for clarifying language describing the process of selecting this topic for prioritization.

Prior Presentations: This work was presented to the PCORI Advisory Panel on Assessment of Prevention, Diagnosis, and Treatment Options on January 13, 2015, during a public session.

Conflict of Interest: The authors do not have any conflicts of interest to disclose. 
Corresponding Author: Gillian D. Sanders, Ph.D.; Department of Medicine, Duke University School of Medicine, Durham, NC, USA (e-mail: gillian.sanders@dm.duke.edu).

\section{REFERENCES}

1. Kong MH, Fonarow GC, Peterson ED, et al. Systematic review of the incidence of sudden cardiac death in the United States. J Am Coll Cardiol. 2011;57(7):794-801.

2. Zipes DP, Wellens HJ. Sudden cardiac death. Circulation. 1998;98(21):2334-51.

3. Moss AJ, Hall WJ, Cannom DS, et al. Improved survival with an implanted defibrillator in patients with coronary disease at high risk for ventricular arrhythmia. Multicenter Automatic Defibrillator Implantation Trial Investigators. N Engl J Med. 1996;335(26):1933-40.

4. Buxton AE, Lee KL, Fisher JD, et al. A randomized study of the prevention of sudden death in patients with coronary artery disease. Multicenter Unsustained Tachycardia Trial Investigators. [Erratum appears in N Engl J Med. 2000;342(17):1300]. N Engl J Med. 1999;341(25):188290.

5. Moss AJ, Zareba W, Hall WJ, et al. Prophylactic implantation of a defibrillator in patients with myocardial infarction and reduced ejection fraction. N Engl J Med. 2002;346(12):877-83.

6. Kadish A, Dyer A, Daubert JP, et al. Prophylactic defibrillator implantation in patients with nonischemic dilated cardiomyopathy. N Engl J Med. 2004;350(21):2151-8.

7. Bardy GH, Lee KL, Mark DB, et al. Amiodarone or an implantable cardioverter-defibrillator for congestive heart failure.[Erratum appears in $\mathrm{N}$ Engl J Med. 2005;352(20):2146]. N Engl J Med. 2005;352(3):225-37.

8. Epstein AE, DiMarco JP, Ellenbogen KA, et al. ACC/AHA/HRS 2008 guidelines for device-based therapy of cardiac rhythm abnormalities: a report of the American College of Cardiology/American Heart Association Task Force on Practice Guidelines (Writing Committee to Revise the ACC/ AHA/NASPE 2002 Guideline Update for Implantation of Cardiac Pacemakers and Antiarrhythmia Devices): developed in collaboration with the American Association for Thoracic Surgery and Society of Thoracic Surgeons.[Erratum appears in Circulation. 2009; 120(5):e34-5]. Circulation. 2008; 117(21):e350-408.

9. Hess PL, Al-Khatib SM, Han JY, et al. Survival benefit of the primary prevention implantable cardioverter-defibrillator among older patients: does age matter? A patient-level meta-analysis of 5 clinical trials. Circ Cardiovasc Qual Outcomes. In press.

10. Hess PL, Grau-Sepulveda MV, Hernandez AF, et al. Age differences in the use of implantable cardioverter-defibrillators among older patients hospitalized with heart failure. J Cardiovasc Electrophysiol. 2013;24(6):664-71.

11. Kremers MS, Hammill SC, Berul CI, et al. The National ICD Registry Report: version 2.1 including leads and pediatrics for years 2010 and 2011. Heart Rhythm. 2013;10(4):e59-65.

12. Epstein AE, Kay GN, Plumb VJ, et al. Implantable cardioverterdefibrillator prescription in the elderly. Heart Rhythm. 2009;6(8):1136-43.

13. Chang SM, Carey TS, Kato EU, Guise JM, Sanders GD. Identifying research needs for improving health care. Ann Intern Med. 2012;157(6):439-45.

14. Al-Khatib SM, Hellkamp AS, Hernandez AF, et al. Trends in use of implantable cardioverter-defibrillator therapy among patients hospitalized for heart failure: have the previously observed sex and racial disparities changed over time? Circulation. 2012;125(9):1094-101.

15. Curtis LH, Al-Khatib SM, Shea AM, et al. Sex differences in the use of implantable cardioverter-defibrillators for primary and secondary prevention of sudden cardiac death. JAMA. 2007;298(13): 1517-24.

16. Al-Khatib SM, Sanders GD, O'Brien SM, et al. Do physicians' attitudes toward implantable cardioverter defibrillator therapy vary by patient age, gender, or race? Ann Noninvasive Electrocardiol. 2011;16(1):77-84.

17. Gasparini M, Proclemer A, Klersy C, et al. Effect of long-detection interval vs standard-detection interval for implantable cardioverter- defibrillators on antitachycardia pacing and shock delivery: the ADVANCE III randomized clinical trial. JAMA. 2013;309(18):1903-11.

18. Moss AJ, Schuger C, Beck CA, et al. Reduction in inappropriate therapy and mortality through ICD programming. N Engl J Med. 2012;367(24):2275-83.

19. Dewland TA, Pellegrini CN, Wang $\mathbf{Y}$, et al. Dual-chamber implantable cardioverter-defibrillator selection is associated with increased complication rates and mortality among patients enrolled in the NCDR implantable cardioverter-defibrillator registry. J Am Coll Cardiol. 2011;58(10):1007-13.

20. Krahn AD, Lee DS, Birnie D, et al. Predictors of short-term complications after implantable cardioverter-defibrillator replacement: results from the Ontario ICD Database. Circ Arrhythm Electrophysiol. 2011;4(2):136-42.

21. Poole JE, Gleva MJ, Mela T, et al. Complication rates associated with pacemaker or implantable cardioverter-defibrillator generator replacements and upgrade procedures: results from the REPLACE registry. Circulation. 2010;122(16):1553-61.

22. Lee DS, Krahn AD, Healey JS, et al. Evaluation of early complications related to De Novo cardioverter defibrillator implantation insights from the Ontario ICD database. J Am Coll Cardiol. 2010;55(8):774-82.

23. Almendral J, Arribas F, Wolpert C, et al. Dual-chamber defibrillators reduce clinically significant adverse events compared with single-chamber devices: results from the DATAS (Dual chamber and Atrial Tachyarrhythmias Adverse events Study) trial. Europace. 2008;10(5):528-35.

24. Friedman PA, McClelland RL, Bamlet WR, et al. Dual-chamber versus single-chamber detection enhancements for implantable defibrillator rhythm diagnosis: the detect supraventricular tachycardia study. Circulation. 2006;113(25):2871-9.

25. Ricci RP, Quesada A, Almendral J, et al. Dual-chamber implantable cardioverter defibrillators reduce clinical adverse events related to atrial fibrillation when compared with single-chamber defibrillators: a subanalysis of the DATAS trial. Europace. 2009;11(5):587-93.

26. Wilkoff BL, Cook JR, Epstein AE, et al. Dual-chamber pacing or ventricular backup pacing in patients with an implantable defibrillator: the Dual Chamber and VVI Implantable Defibrillator (DAVID) Trial. JAMA. 2002;288(24):3115-23.

27. Kolb C, Deisenhofer I, Schmieder S, et al. Long-term follow-up of patients supplied with single-chamber or dual-chamber cardioverter defibrillators. Pacing Clin Electrophysiol. 2006;29(9):946-52.

28. Olshansky B, Day JD, Moore S, et al. Is dual-chamber programming inferior to single-chamber programming in an implantable cardioverterdefibrillator? Results of the INTRINSIC RV (Inhibition of Unnecessary RV Pacing With AVSH in ICDs) study. Circulation. 2007;115(1):9-16.

29. Wilkoff BL, Kudenchuk PJ, Buxton AE, et al. The DAVID (Dual Chamber and VVI Implantable Defibrillator) II trial. J Am Coll Cardiol. 2009;53(10):872-80.

30. Deisenhofer I, Kolb C, Ndrepepa G, et al. Do current dual chamber cardioverter defibrillators have advantages over conventional single chamber cardioverter defibrillators in reducing inappropriate therapies? A randomized, prospective study. J Cardiovasc Electrophysiol. $2001 ; 12(2): 134-42$.

31. Theuns DA, Klootwijk AP, Goedhart DM, Jordaens LJ. Prevention of inappropriate therapy in implantable cardioverter-defibrillators: results of a prospective, randomized study of tachyarrhythmia detection algorithms. J Am Coll Cardiol. 2004;44(12):2362-7.

32. Bansch D, Steffgen F, Gronefeld G, et al. The $1+1$ trial: a prospective trial of a dual- versus a single-chamber implantable defibrillator in patients with slow ventricular tachycardias. Circulation. 2004;110(9):1022-9.

33. Kusumoto FM, Calkins H, Boehmer J, et al. HRS/ACC/AHA expert consensus statement on the use of implantable cardioverter-defibrillator therapy in patients who are not included or not well represented in clinical trials. J Am Coll Cardiol. 2014;64(11):1143-77.

34. Weiss R, Knight BP, Gold MR, et al. Safety and efficacy of a totally subcutaneous implantable-cardioverter defibrillator. Circulation. 2013;128(9):944-53.

35. Bardy GH, Smith WM, Hood MA, et al. An entirely subcutaneous implantable cardioverter-defibrillator. N Engl J Med. 2010;363(1):36-44. 